sitive $\mathrm{NaCl}$ cotransport. J. Clin. Invest. 115:1379-1387. doi:10.1172/JCI200522452.

8. Forster, I.C., Hernando, N., Biber, J., and Murer, H. 2006. Proximal tubular handling of phosphate: a molecular perspective. Kidney Int 70:1548-1559

9. Tenenhouse, H.S. 2007. Phosphate transport: Molecular basis, regulation and pathophysiology. J. Steroid Biochem. Mol. Biol. 103:572-577.

10. Beck, L., et al. 1998. Targeted inactivation of Npt2 in mice leads to severe renal phosphate wasting, hypercalciuria, and skeletal abnormalities. Proc. Natl. Acad. Sci. U. S. A. 95:5372-5327.

11. Berndt, T., and Kumar, R. 2007. Phosphatonins and the regulation of phosphate homeostasis. Annu. Rev. Physiol. 69:341-359.

12. Lalioti, M.D., et al. 2006. Wnk4 controls blood pressure and potassium homeostasis via regulation of mass and activity of the distal convoluted tubule. Nat. Genet. 38:1124-1132.

13. Deliot, N., et al. 2005. Parathyroid hormone treatment induces dissociation of type lla $\mathrm{Na}$ Pi cotransporter- $\mathrm{Na} / \mathrm{H}$ exchanger regulatory factor-1 complexes. Am. J. Physiol. Cell Physiol. 289:C159-C167.
14. Schechtman, D., and Mochly-Rosen, D. 2001. Adaptor proteins in protein kinase C-mediated signal transduction. Oncogene. 20:6339-6347.

15. Tasken, K., and Aandahl, E.M. 2004. Localized effects of cAMP mediated by distinct routes of protein kinase A. Physiol. Rev. 84:137-167.

16. Shenolikar, S., Voltz, J.W., Cunningham, R., and Weinman, E.J. 2004. Regulation of ion transport by the NHERF family of PDZ proteins. Physiology. 19:362-369.

17. Weinman, E.J., Cunningham, R., Wade, J.B., and Shenolikar, S. 2005. The role of NHERF-1 in the regulation of renal proximal tubule sodium-hydrogen exchanger 3 and sodium-dependent phosphate cotransporter 2a. J. Physiol. 567:27-32.

18. Weinman, E.J., Hall, R.A., Friedman, P.A., Liu-Chen, L.-Y., and Shenolikar, S. 2006. The association of NHERF adaptor proteins with $G$ protein-coupled receptors and receptor tyrosine kinases. Ann. Rev. Physiol. 68:491-505.

19. He, J., Lau, A.G., Yaffe, M.B., and Hall, R.A. 2001 Phosphorylation and cell cycle-dependent regulation of $\mathrm{Na} / \mathrm{H}$ exchanger regulatory factor- 1 by Cdc2 kinase. J. Biol. Chem. 276:41559-41565

20. Gisler, S.M., et al. 2001. Interaction of the type IIa
$\mathrm{Na} / \mathrm{Pi}$ cotransporter with PDZ proteins. J. Biol. Chem. 276:9206-9213.

21. Shenolikar, S., Voltz, J.W., Minkoff, C.M., Wade, J.B., and Weinman, E.J. 2002. Targeted disruption of the mouse NHERF-1 gene promotes internalization of proximal tubule sodium-phosphate cotransporter type IIa and renal phosphate wasting. Proc. Natl. Acad. Sci. U. S. A. 99:11470-11475.

22. Capuano, P., et al. 2007. Defective coupling of apical PTH receptors to phospholipase C prevents internalization of the $\mathrm{Na}^{+}$-phosphate cotransporter NaPi-IIa in Nherf1-deficient mice. Am. J. Physiol. Cell Pbysiol. 292:C927-C934.

23. Wilson, F.H., et al. 2001. Human hypertension caused by mutations in WNK kinases. Science. 293:1107-1112

24. Kahle, K.T., et al. 2006. WNK protein kinases modulate cellular Cl- flux by altering the phosphorylation state of the $\mathrm{Na}-\mathrm{K}-\mathrm{Cl}$ and $\mathrm{K}-\mathrm{Cl}$ cotransporters. Physiology. 21:326-335.

25. Rinehart, J., et al. 2005. WNK3 kinase is a positive regulator of NKCC2 and NCC, renal cation$\mathrm{Cl}$ - cotransporters required for normal blood pressure homeostasis. Proc. Natl. Acad. Sci. U. S. A. 102:16777-16782.

\title{
Macrophages feel their age in macular degeneration
}

\author{
Martine J. Jager ${ }^{1}$ and Caroline C.W. Klaver ${ }^{2,3}$
}

1Department of Ophthalmology, Leiden University Medical Center, Leiden, The Netherlands. 2Department of Ophthalmology and Department of Epidemiology and Biostatistics, Erasmus Medical Center, Rotterdam, The Netherlands. ${ }^{3}$ Netherlands Institute for Neuroscience, Amsterdam, The Netherlands.

\begin{abstract}
Macular degeneration, during which the posterior part of the eye known as the macula suffers from thinning, atrophy, and bleeding caused by abnormal angiogenesis (blood vessel formation), predominantly affects elderly adults and results in the loss of central vision. In this issue of the $J C I$, Kelly et al. investigate the regulation of innate immune cells, specifically macrophages, in ocular neovascularization following eye injury in mice (see the related article beginning on page 3421). They found that, as the mice aged, increased expression of IL-10 by senescent macrophages and changes in their expression of other cytokines altered the ability of these cells to restrain trauma-induced angiogenesis in the eye. These data provide insight into the effect of senescence on macrophage function and angiogenesis and have important implications for age-related diseases such as macular degeneration.
\end{abstract}

\section{Neovascularization and the eye}

The eye is a delicate structure with a finely developed blood vessel network, and any disturbances to this delicate system may lead to new blood vessel formation (angiogenesis) in areas of the eye that normally do not contain blood vessels, which may interfere with the function of the eye. In

Nonstandard abbreviations used: AMD, age-related macular degeneration; FasL, Fas ligand.

Conflict of interest: The authors have declared that no conflict of interest exists.

Citation for this article: J. Clin. Invest. 117:3182-3184 (2007). doi:10.1172/JCI34070. ocular diseases, abnormal blood vessel formation (neovascularization) often has a detrimental effect on vision. An important example of a disease in which the formation of abnormal blood vessels affects the eye is diabetic retinopathy, in which closure of retinal capillaries leads to ischemia, followed by the production of the proangiogenic growth factor VEGF, which induces the development of new blood vessels of an inferior type (1). Such vessels tend to bleed or grow into locations where they damage vision. Another example is age-related macular degeneration (AMD). While the central area of the retina, the macula, is normally devoid of blood vessels, in AMD, aberrant blood vessels develop in this area and destroy central vision. In response to hypoxia, these blood vessels grow from the underlying choroid through Bruch's membrane into the subretinal space (Figure 1). This type of AMD is known as neovascular or wet AMD; together with geographic atrophy and dry AMD (a discrete, central area with depigmentation and breakdown of light-sensitive cells in the macula), these are the clinical forms known as AMD. Advanced AMD is a frequent cause of severe visual impairment among the elderly. The estimated prevalence of AMD is $11 \%$ in those aged 80 years and over (2), and 95\% of cases of legal blindness in this age group are caused by AMD.

Macrophages and neovascularization Macrophages have been shown to have both pro- and antiangiogenic effects following tissue injury in the eye, which suggests that their activity is carefully regulated in a complex manner, likely by local cytokines: on one hand, it has for instance been shown that macrophages are essential for removal of the hyaloid vessels; on the other hand, macrophages are necessary to 


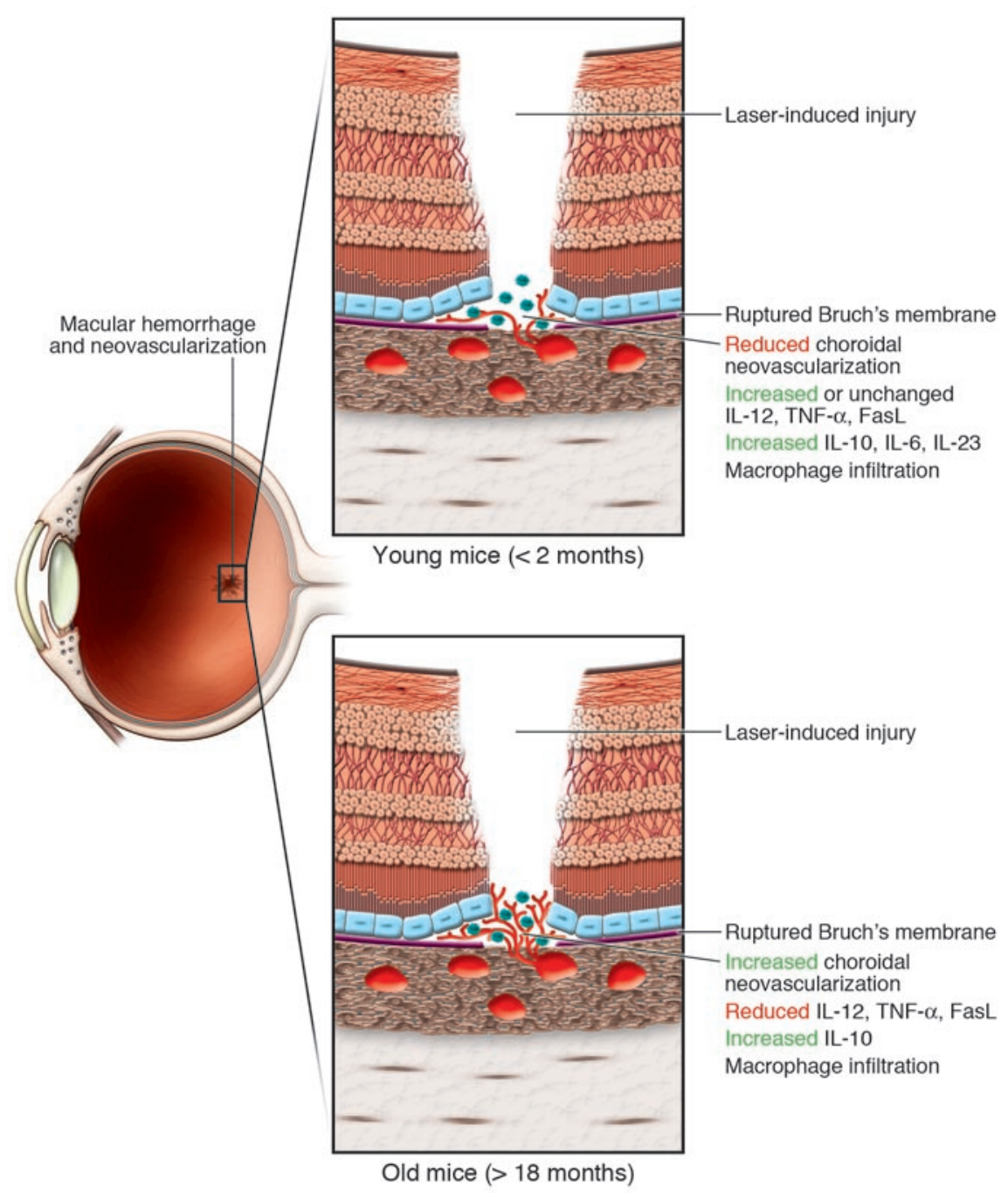

stimulate inflammation-induced neovascularization $(3,4)$. Macrophages thus play a dual role, and have recently been found to be physically associated with growing as well as regressing vessels (5). It has also been reported that age can influence angiogenesis (6). Therefore, in their study in this issue of the JCI, Kelly et al. (7) sought to further investigate the influence of macrophages on blood vessel formation in the eye, specifically the factors, age or otherwise, that regulate the pro- or antiangiogenic nature of macrophage function during neovascularization of the eye.

In order to study blood vessel formation in the retina, Kelly et al. (7) used a previously developed animal model that possesses a clinical phenotype much like that observed in diabetic retinopathy: laserinduced eye injury causes retinal ischemia in the murine eye, which is subsequently followed by choroidal neovascularization (6). Vessel growth can be examined via sev- eral imaging techniques, and this growth can then be manipulated. Kelly et al. used a laser to induce rupture of Bruch's membrane in mice less than 2 months of age or older than 18 months of age. Evaluation of the angiogenic response 7 days after injury revealed that, surprisingly, the older mice had significantly more macrophage-rich neovascularization compared with the young mice, suggesting that their antiangiogenic responses were impaired.

As prior studies showed that macrophages play a role in neovascularization after laser-induced injury $(8,9)$, and as histology of laser-induced injuries showed massive infiltration of the injury site with macrophages (10), Kelly et al. sought to determine whether there was any functional difference between macrophages from young and older mice with respect to their ability to inhibit angiogenesis (7). The authors isolated macrophages from young or old mice and injected these cells into the

\section{Figure 1}

Role of normal versus senescent macrophages in ocular neovascularization. In this issue, Kelly et al. (7) report that following laser-induced injury of the retina, macrophage infiltration occurs in both young ( $<2$ months) and old (>18 months) mice. However, this macrophage infiltration is associated with neovascularization in older mice only. RT-PCR analyses of macrophages isolated from the retinae of older mice revealed lower expression levels of TNF- $\alpha$, FasL, and IL- 6 than in macrophages in the retinae of younger mice. An increase in IL-10 expression was observed in the retinae of all mice, although baseline levels were higher in old mice. These data suggest that as the mice age, increased IL-10 expression and altered cytokine expression limits the ability of senescent macrophages to regulate injury-induced neovascularization in the eye. The authors' findings provide insight into the role of macrophages during neovascularization in AMD. eyes of old mice on the day of laser-induced injury. Macrophages from the young mice inhibited the subsequent choroidal neovascularization; however, macrophages from the old mice did not, which indicates that macrophages from young mice had a dominant effect, as they were able to overcome the lack of inhibition of angiogenesis that was typical in older mice. Surprisingly, injection of macrophages incubated in IL-10 did not have the same dramatic effect, although they appeared to inhibit angiogenesis slightly.

The authors looked to the cytokine profile of the macrophages in young versus old mice for clues to the potential differences in macrophage activity (7). They found that macrophage-rich choroidal neovascularization lesions in the older mice had significantly reduced expression of IL-12, TNF- $\alpha$, and Fas ligand (FasL) and high IL-10 expression compared with young mice. This observation was particularly 
interesting given that this research group had previously demonstrated that IL-10-/mice have a reduced angiogenic response following laser-induced eye injury (6).

Finally, incubating endothelial cells in vitro with macrophages from old and young mice again showed a differential effect, with the macrophages from old mice stimulating the outgrowth of endothelial cells and the macrophages from young mice inhibiting endothelial cell growth (7).

\section{Age matters}

The study by Kelly et al. (7) shows us that age matters. Older mice were not able to inhibit blood vessel growth, and this was linked to a loss of some intracellular cytokines, a loss of expression of FasL, and an increase in the production of IL-10. It may well be that similar changes occur in humans. The frequency of subretinal neovascularization occurring in human AMD shows a steep rise with age (2): among those younger than 50 years the frequency is naught; in those aged 70 years it is $1 \%-2 \%$, and in individuals aged 80 years and over it is greater than $8 \%$.

Prior to the development of AMD, specific changes can be observed in the retina. These changes include the accumulation of yellow or white extracellular material in small lesions known as drusen, and histological analysis of drusen has shown that they are composed of proteins related to inflammation, such as complement proteins, and contain HLA-DR-positive structures that are considered to be choroidal dendritic cells (8). Other histological studies showed that macrophages are actively involved in the promotion of neovascular proliferation in AMD and that they are present in drusen (9). As drusen occur mainly in elderly people, it is possible that these dendritic cells or macrophages are only able to stimulate vessel formation and have lost their capacity to inhibit angiogenesis when local inflammation stimulates the production of VEGF. While we do not know exactly why drusen and AMD develop, recent evidence points to the existence of both genetic and environmental underlying factors. Genes involved in the complement cascade, such as Complement Factor H, C2, C3, and Factor B $(10,11)$, appear to be strong genetic determinants of disease, and smoking has been shown to be an important environmental risk factor in AMD (12). Experimental studies in mice showed that exposure to cigarette smoke led to the development of retinal changes, such as thickening of Bruch's membrane and accumulation of deposits within Bruch's membrane, that resemble the changes that occur in early AMD (13).

\section{Macrophages in ocular tumors}

Macrophages may also influence the behavior of tumors. Human intraocular tumors have been shown to contain high numbers of macrophages, and a significant association has been observed between the number of macrophages and the number of blood vessels in such tumors (14). In addition, both parameters were associated with an increased chance of dying as a result of tumor metastases. Because intraocular melanomas occur with higher incidence in older people, it may also be than an influx of "old" macrophages stimulates blood vessel formation in these tumors. Blood vessels are critical for tumor metastasis, because tumors spread hematogenously. Intriguingly, similar to the earlier findings of these authors demonstrating that depletion of macrophages in young mice induced neovascularization (6), depletion of macrophages in murine eyes prior to tumor cell implantation did not stop tumor growth (15). As far as we are aware, no studies have been undertaken on the effect of age on tumor growth in an experimental murine intraocular tumor model.

\section{Conclusions}

The description by Kelly et al. (7) of the different angiogenic properties of macrophages in young and old mice helps us to better understand why certain diseases have a tendency to occur specifically in the elderly. As the production of cytokines such as IL-10 play a role in angiogenesis, therapeutic avenues that change the production of such cytokines might be investigated. As genetic studies may identify those individuals at higher risk of developing AMD when they age, developing early intervention measures may contribute to the prevention of blindness in the elderly.

Address correspondence to: M.J. Jager, Department of Ophthalmology, Leiden University Medical Center, PO Box 9600, 2300 RC Leiden, The Netherlands. Phone: 31-71-5263097; Fax: 31-71-5248222; E-mail: m.j.jager@lumc.nl.
1. Zhang, S.X., and Ma, J.-X. 2007. Ocular neovascularization: Implication of endogenous angiogenic inhibitors and potential therapy. Prog. Retin. Eye Res. 26:1-37.

2. Friedman, D.S., et al. 2004. Prevalence of age-related macular degeneration in the United States. Arch. Ophthalmol. 122:564-572.

3. Lang, R.A., and Bishop, M.J. 1993. Macrophages are required for cell death and tissue remodeling in the developing mouse eye. Cell. 74:453-462.

4. Cursiefen, C., et al. 2004. VEGF-A stimulates lymphangiogenesis and hematogenesis in inflammatory neovascularization via macrophage recruitment. J. Clin. Invest. 113:1040-1050. doi:10.1172/JCI200420465.

5. Shen, J., et al. 2007. In vivo immunostaining demonstrates macrophages associate with growing and regressing vessels. Invest. Ophthalmol. Vis. Sci. 48:4335-4341.

6. Apte, R.S., Richter, J., Herndon, J., and Ferguson, T.A. 2006. Macrophages inhibit neovascularization in a murine model of age-related macular degeneration. PLoS. Med. 3:e310.

7. Kelly, J., Khan, A.A., Yin, J., Ferguson, T.A., and Apte, R.S. 2007. Senescence regulates macrophage activation and angiogenic fate at sites of tissue injury in mice. J. Clin. Invest. 117:3421-3426. doi:10.1172/JCI32430.

8. Espinosa-Heidmann, D.G., et al. 2002. Age as an independent risk factor for severity of experimental choroidal neovascularization. Invest. Ophthalmol. Vis. Sci. 43:1567-1573.

9. Espinosa-Heidmann, D.G., et al. 2003. Macrophage depletion diminishes lesion size and severity in experimental choroidal neovascularization. Invest. Ophthalmol. Vis. Sci. 44:3586-3592.

10. Sakurai, E., Anand, A., Ambati, B.K., Van Rooijen, N., and Ambati, J. 2003. Macrophage depletion inhibits experimental choroidal neovascularization. Invest. Ophthalmol. Vis. Sci. 44:3578-3585.

11. Hageman, G.S., and Mullins, R.F. Association of major histocompatibility class II antigens with core subdomains present within human ocular drusen. In Antigen-presenting cells and the eye. M. Zierhut, H.-G. Rammensee, and J.W. Streilein, editors. Informa Healthcare USA, Inc. New York, New York, USA. 209-216.

12. Penfold, P.L., Madigan, M.C., Gillies, M.C., and Provis, J.M. 2001. Immunological and aetiological aspects of macular degeneration. Prog. Retin. Eye Res. 20:385-414.

13. Maller, J., et al. 2006. Common variation in three genes, including a noncoding variant in $\mathrm{CFH}$, strongly influences risk of age-related macular degeneration. Nat. Genet. 38:1055-1059.

14. Despriet, D.D.G., et al. 2006. Complement factor $\mathrm{H}$ polymorphism, complement activators, and risk of age-related macular degeneration. JAMA. 296:301-309.

15. Van Leeuwen, R., Klaver, C.C., Vingerling, J.R., Hofman, A., and de Jong, P.T. 2003. Epidemiology of age-related maculopathy: a review. Eur. J. Epidemiol. 18:845-854.

16. Espinosa-Heidmann, D.G., et al. 2006. Cigarette smoke-related oxidants and the development of sub-RPE deposits in an experimental animal model of dry AMD. Invest. Ophthalmol. Vis. Sci. 47:729-737.

17. Makitie, T., Summanen, P., Tarkkanen, A., and Kivela, T. 2001. Tumor-infiltrating macrophages (CD68(+) cells) and prognosis in malignant melanoma. Invest. Ophthalmol. Vis. Sci. 42:1414-1421.

18. Boonman, Z.F., et al. 2006. Macrophages are vital in spontaneous intraocular tumor eradication. Invest. Ophthalmol. Vis. Sci. 47:2959-2965. 